\title{
Assessment of two missense polymorphisms (rs4762 and rs699) of the angiotensinogen gene and stroke
}

\author{
HYUN-KYUNG PARK ${ }^{1}$, MYUNG-CHUN KIM ${ }^{1}$, SUNG-MIN KIM ${ }^{2}$ and DAE JEAN JO ${ }^{2}$ \\ Departments of ${ }^{1}$ Emergency Medicine and ${ }^{2}$ Neurosurgery, School of Medicine, \\ Kyung Hee University Hospital at Gangdong, Seoul, Republic of Korea
}

Received August 6, 2012; Accepted October 25, 2012

DOI: $10.3892 /$ etm.2012.790

\begin{abstract}
The renin-angiotensin system has an important role in the pathogenesis of stroke. We investigated whether two missense single nucleotide polymorphisms (SNPs; rs4762, Thr207Met, T207M; and rs699, Met268Thr, M268T) of angiotensinogen (AGT; serpin peptidase inhibitor, clade A, member 8) are associated with the development and clinical phenotypes of ischemic stroke (IS) and intracerebral hemorrhage (ICH). We analyzed 197 stroke patients (120 IS and 77 ICH) and 301 control subjects. The patients were classified into subgroups in accordance to the scores of the National Institutes of Health Stroke Survey (NIHSS, $<6$ and $\geq 6$ ) and Modified Barthel Index (MBI, $<60$ and $\geq 60$ ). Multiple logistic regression models were used to analyze the genotype and allele distributions of each SNP. One of the missense SNPs, rs4762 (T207M) was associated with the development of $\mathrm{ICH}(\mathrm{P}=0.038$ in log-additive model and $\mathrm{P}=0.021$ in allele distributions). The $\mathrm{T}$ allele frequency of T207M was higher in the ICH group (16.2\%) compared with the control group (9.6\%). The TC haplotype frequency differed significantly between the ICH and control groups $(\mathrm{P}=0.014)$. With regard to clinical features, T207M correlated with the NIHSS scores of the ICH patients $(\mathrm{P}=0.039$ in codominant1, $\mathrm{P}=0.015$ in dominant, $\mathrm{P}=0.011$ in overdominant and $\mathrm{P}=0.039$ in log-additive models). However, the two missense SNPs, rs4762 and rs699, were not associated with IS and its clinical features, including NIHSS and MBI scores. These data suggest that a missense SNP (rs4762, T207M) of the AGT gene may be associated with the development of $\mathrm{ICH}$ and contribute to the neurological functional levels of ICH patients.
\end{abstract}

\section{Introduction}

Environmental and genetic factors contribute to stroke pathogenesis (1-3). A wide range of genetic studies have reported

Correspondence to: Dr Dae Jean Jo, Department of Neurosurgery, School of Medicine, Kyung Hee University, 149 Sangil-dong, Gangdong-gu, Seoul 134-727, Republic of Korea

E-mail: apuzzo@hanmail.net

Key words: angiotensinogen, haplotype, intracerebral hemorrhage, ischemic stroke, single nucleotide polymorphism an association between stroke and single nucleotide polymorphisms (SNPs) of certain candidate genes (4-7). During the years 2001-2010, several researchers published studies on the correlation between stroke risk in Korean patients and the SNPs of candidate genes, including neuropeptide Y (8), methylenetetrahydrofolate reductase $(\mathrm{NAD}(\mathrm{P}) \mathrm{H})(9,10)$, Fc fragment of IgG, low affinity IIa, receptor (CD32) (11), interleukin 1 receptor antagonist $(12,13)$, thromboxane A2 receptor (14), thromboxane A synthase 1 (platelet) (14), phosphodiesterase 4D cAMP-specific (15), chemokine (C-C motif) ligand 5 (16), interleukin 4 (16), fibrinogen $\beta$ chain (17), apolipoprotein E (18), paraoxonase 1 (19), paraoxonase 2 (19), 5-methyltetrahydrofolate-homocysteine methyltransferase (10), peroxisome proliferator-activated receptor $\gamma(20)$, Klotho (21), tumor necrosis factor (12), interleukin $1 \beta$ (12), and Fas (TNF receptor superfamily, member 6) (22).

The renin-angiotensin system (RAS) plays a key role in the regulation of blood pressure and the homeostasis of fluid and electrolytes (23). In brief, angiotensinogen (AGT; serpin peptidase inhibitor, clade A, member 8 ) is synthesized in the liver. AGT is a circulating substrate from which renin cleaves angiotensin I. Angiotensin I is converted to angiotensin II by angiotensin I converting enzyme (peptidyl-dipeptidase A) 1 (ACE, also known as kininase II). Angiotensin II, a potent pressor substrate, stimulates aldosterone biosynthesis. In the central nervous system (CNS), angiotensin II also stimulates drinking and increases vasopressin and adrenocorticotropic hormone. The RAS is involved in the pathogenesis of stroke $(23,24)$. Several studies have demonstrated associations between gene polymorphisms concerning the RAS and stroke (25-27). Although the RAS may be implicated in the pathogenesis of stroke, the genetic determinants remain unknown. The aim of this study was to assess whether AGT SNPs were associated with the development and clinical features of stroke, specifically ischemic stroke (IS) and intracerebral hemorrhage (ICH) in a Korean population.

\section{Subjects and methods}

Study subjects. The subjects were stroke patients who visited the Departments of Neurosurgery and Emergency Medicine in the East-West Neomedical Center and Kyung Hee Medical Center (Seoul, Korea). We recruited 120 IS and 77 ICH patients (Table I) and excluded patients with accidental or iatrogenic 
strokes, transient ischemic attack, brain tumors and congenital brain disorders. Each stroke patient underwent computed tomography and magnetic resonance imaging. We recruited 301 controls through a general health check-up program. Subjects with neurological diseases, ischemic heart diseases, immunological diseases or any severe diseases were excluded. This study was conducted in accordance with the guidelines of the Declaration of Helsinki and approved by the ethics review committee of the Medical Research Institute, School of Medicine, Kyung Hee University. Informed consent was obtained from all subjects. If a stroke patient was incommunicative, we obtained informed consent from a close relative or guardian.

Subgroups of stroke patients. All stroke patients were classified into one of two clinical subgroups according to the respective results of the National Institutes of Health Stroke Survey (NIHSS) and Modified Barthel Index (MBI). The severity of 13 neurologic symptoms was measured by the NIHSS to evaluate the neurological functional levels of the patient. The quality of 10 general life activities was also measured by the MBI to evaluate the activity of daily living (ADL).

SNP genotyping. We selected two well-known missense SNPs (rs4762, Thr207Met, T207M; and rs699, Met268Thr, M268T) of the AGT gene (http:/www.ncbi.nlm.nih.gov/ SNP; BUILD 132). The previously reported codon numbers of rs4762 and rs699 are 174 and 235, respectively. T207M and M268T refer to a threonine-to-methionine exchange in codon 207 and a methionine-to-threonine exchange in codon 268, respectively. Peripheral blood samples were collected in EDTA or heparin tubes from all subjects. Genomic DNA was extracted using a QIAamp ${ }^{\circledR}$ DNA mini kit (Qiagen, Valencia, CA, USA) and the genotypes of the two SNPs were determined by direct sequencing (Macrogen Inc., Seoul, Korea). We carried out polymerase chain reactions (PCRs) using the sense and antisense primers of each SNP (Table II) under the following conditions: 40 cycles at $94^{\circ} \mathrm{C}$ for $30 \mathrm{sec}, 58^{\circ} \mathrm{C}$ for $30 \mathrm{sec}$ and $72^{\circ} \mathrm{C}$ for $30 \mathrm{sec}$, and 1 cycle at $72^{\circ} \mathrm{C}$ for $5 \mathrm{~min}$ as a final extension step. The PCR products were sequenced using an ABI PRISM 3730xl analyzer (PE Applied Biosystems, Foster City, CA, USA). SeqMan II software (DNASTAR, Inc., Madison, WI, USA) was used to analyze the sequencing data.

Statistical analysis. SNPStats (http://bioinfo.iconcologia.net/ index.php?module=Snpstats), SNPAnalyzer Pro (Istech Corp., Goyang, Korea) and HelixTree (Golden Helix, Inc., Bozeman, MT, USA) were used to determine odds ratios (ORs), 95\% confidence intervals (CIs), and P-values adjusting for age and gender as covariables. Hardy-Weinberg equilibrium (HWE) was calculated by the Chi-square test. Multiple logistic regression models (codominant1, codominant 2 , dominant, recessive and log-additive) were employed to analyze the genetic data. The linkage disequilibrium (LD) block and haplotypes between two SNPs were estimated using Haploview 4.2 (http://www.broadinstitute.org/scientific-community/science/ programs/medical-and-population-genetics/haploview). For numbers $<5$, the P-value was corrected by Fisher's exact test. Statistical significance was tested using SPSS 15.0 (SPSS Inc.,
Table I. Clinical features of study subjects.

\begin{tabular}{lccc}
\hline Feature & IS & ICH & Control \\
\hline Total number (n) & 120 & 77 & 301 \\
Male/female (n) & $68 / 52$ & $45 / 32$ & $163 / 138$ \\
Age (mean \pm SD, years) & $65.7 \pm 12.1$ & $56.2 \pm 12.5$ & $61.1 \pm 10.1$ \\
NIHSS (score) & & & \\
$<6$ & 56 & 24 & \\
$\geq 6$ & 56 & 49 & \\
MBI (score) & & & \\
$<60$ & 70 & 53 & \\
$\geq 60$ & 25 & 14 & \\
\hline
\end{tabular}

IS, ischemic stroke; ICH, intracerebral hemorrhage; n, number; SD, standard deviation; NIHSS, National Institutes of Health Stroke Survey; MBI, Modified Barthel Index. Stroke patients with inappropriate clinical data were excluded.

Table II. Primer sequences for each SNP.

\begin{tabular}{lccc}
\hline SNP & S/A & $\begin{array}{c}\text { Primer sequence } \\
(5 '-3 ')\end{array}$ & $\begin{array}{c}\text { Size } \\
(\mathrm{bp})\end{array}$ \\
\hline rs4762 & S & CTCTCTCTATCTGGGAGCCTTG & 323 \\
& A & CAATCTTCTCAGCAGCAACATC & \\
rs699 & S & TGTACAGGGCCTGCTAGTGG & 369 \\
& A & ACTGGCTGATCTCAGCTACACA & \\
\hline
\end{tabular}

SNP, single nucleotide polymorphism; bp, base pair; S, sense; A, antisense.

Chicago, IL, USA) and $\mathrm{P}<0.05$ was considered to indicate a statistically significant result.

\section{Results}

Clinical features of study subjects. The clinical features of the stroke and control subjects are shown in Table I. The control group ( $\mathrm{n}=301)$ consisted of 163 males and 138 females. The mean age of the controls was $61.1 \pm 10.1$ (mean \pm SD) years. The IS group $(n=120)$ comprised 68 males and 52 females, and the mean age of the IS patients was $65.7 \pm 12.1$ years. The ICH group $(n=77)$ had a mean age of $56.2 \pm 12.5$ years, and consisted of 45 males and 32 females (Table I). The mean ages did not differ significantly between the stroke patients (IS+ICH) and control subjects ( $\mathrm{P}>0.05$, data not shown), whereas the mean ages of the IS and ICH patients each differed from that of the controls $(\mathrm{P}<0.05$, data not shown). Therefore, we adjusted for age and gender as covariates when obtaining statistical results from the genetic data analyses. The stroke patients were classified into one of two clinical subgroups in accordance with the NIHSS scores $(<6$ and $\geq 6)$ and MBI scores $(<60$ and $\geq 60)$. The numbers of IS and ICH patients with NIHSS scores $<6$ were 56 and 24 , respectively and with NIHSS scores $\geq 6$ were 56 and 49 , respectively. The 
Table III. Genotype and allele frequencies of AGT SNPs in IS and control subjects.

\begin{tabular}{|c|c|c|c|c|c|c|c|}
\hline SNP & Genotype/allele & $\begin{array}{c}\text { Control } \\
\mathrm{n}(\%)\end{array}$ & $\begin{array}{c}\text { IS } \\
\mathrm{n}(\%)\end{array}$ & Model & OR $(95 \% \mathrm{CI})$ & P-value & $\begin{array}{c}\text { Fisher's } \\
\text { exact } \\
\text { P-value }\end{array}$ \\
\hline \multirow[t]{10}{*}{ rs4762 (T207M) } & Genotype & & & & & & \\
\hline & $\mathrm{C} / \mathrm{C}$ & $247(82.1)$ & $91(75.8)$ & Codominant 1 & $1.46(0.85-2.50)$ & 0.15 & \\
\hline & $\mathrm{C} / \mathrm{T}$ & $50(16.6)$ & $27(22.5)$ & Codominant 2 & $1.78(0.31-10.15)$ & 0.73 & 0.66 \\
\hline & $\mathrm{T} / \mathrm{T}$ & $4(1.3)$ & $2(1.7)$ & Dominant & $1.48(0.87-2.50)$ & 0.15 & \\
\hline & & & & Recessive & $1.65(0.29-9.41)$ & 0.58 & 1.00 \\
\hline & & & & Overdominant & $1.44(0.84-2.47)$ & 0.19 & \\
\hline & & & & Log-additive & $1.42(0.89-2.28)$ & 0.15 & \\
\hline & Allele & & & & & & \\
\hline & $\mathrm{C}$ & $544(90.4)$ & $209(87.1)$ & & 1 & & \\
\hline & $\mathrm{T}$ & $58(9.6)$ & $31(12.9)$ & & $1.39(0.87-2.21)$ & 0.16 & \\
\hline \multirow[t]{10}{*}{ rs699 (M699T) } & Genotype & & & & & & \\
\hline & $\mathrm{C} / \mathrm{C}$ & $196(65.5)$ & $78(65.5)$ & Codominant 1 & $0.99(0.62-1.58)$ & 0.91 & \\
\hline & $\mathrm{C} / \mathrm{T}$ & $98(32.8)$ & $38(31.9)$ & Codominant 2 & $1.32(0.29-5.96)$ & 0.58 & 0.69 \\
\hline & $\mathrm{T} / \mathrm{T}$ & $5(1.7)$ & $3(2.5)$ & Dominant & $1.01(0.64-1.59)$ & 0.98 & \\
\hline & & & & Recessive & $1.32(0.29-5.94)$ & 0.72 & 0.69 \\
\hline & & & & Overdominant & $0.98(0.62-1.56)$ & 0.94 & \\
\hline & & & & Log-additive & $1.03(0.68-1.56)$ & 0.9 & \\
\hline & Allele & & & & & & \\
\hline & $\mathrm{C}$ & $490(81.9)$ & $194(81.5)$ & & 1 & & \\
\hline & $\mathrm{T}$ & $108(18.1)$ & $44(18.5)$ & & $1.03(0.70-1.52)$ & 0.89 & \\
\hline
\end{tabular}

numbers of IS and ICH patients with MBI scores $<60$ were 70 and 53, respectively, and with MBI scores $\geq 60$ were 25 and 14, respectively (Table I).

Genetic analysis. Multiple logistic regression analysis with adjustment for age and gender was carried out using the following models: codominant1 (major allele homozygotes vs. heterozygotes), codominant2 (major allele homozygotes vs. minor allele homozygotes), dominant (major allele homozygotes vs. heterozygotes+minor allele homozygotes), recessive (major allele homozygotes+heterozygotes vs. minor allele homozygotes) and log-additive (major allele homozygotes vs. heterozygotes vs. minor allele homozygotes). The genotype and allele frequencies of the two examined SNPs are shown in Tables III and IV. The two missense SNPs (rs4762, Thr207Met, T207M; and rs699, Met268Thr, M268T) of the AGT gene were in HWE in the IS, ICH and control groups ( $>00.05$, data not shown). The T207M and M268T SNPs were not associated with the development of IS (Table III). As shown in Table IV, one of the missense SNPs (T207M) was weakly associated with the development of $\mathrm{ICH}(\mathrm{P}=0.038$; OR, 1.73 ; $95 \%$ CI, 1.04-2.89 in log-additive model). The $\mathrm{T}$ allele frequency of T207M was higher in the ICH group (16.2\%) than in the control group $(9.6 \% ; \mathrm{P}=0.021 ; \mathrm{OR}, 1.82 ; 95 \% \mathrm{CI}$, 1.10-3.02). The genotype and allele frequencies of M268T showed no differences between the $\mathrm{ICH}$ and control groups
(Table IV). These data suggest that the rs4762 (T207M) SNP of the AGT gene may be associated with $\mathrm{ICH}$ and the T allele of rs4762 may be a risk factor for the development of ICH.

Analysis of clinical phenotypes. All stroke patients were divided into clinical subgroups in accordance to the score of the NIHSS $(<6$ and $\geq 6)$ and MBI $(<60$ and $\geq 60)$. As shown in Table V, one of the missense SNPs (T207M) was associated with the NIHSS scores of the ICH patients $(\mathrm{P}=0.039$; OR, 6.33; 95\% CI, 1.25-32.13 in codominant $; \mathrm{P}=0.015$; OR, 4.85; 95\% CI, 1.19-19.65 in dominant; $\mathrm{P}=0.011$; OR, 6.09; 95\% CI, 1.21-30.55 in overdominant; and $\mathrm{P}=0.039$; OR, 3.01; 95\% CI, 0.94-9.62 in log-additive models). The $\mathrm{C} / \mathrm{T}$ genotype frequency of rs 4762 was higher in the NIHSS $\geq 6$ group $(32.6 \%)$ than in the NIHSS $<6$ group $(8.3 \%)$. The $\mathrm{T}$ allele frequency of rs4762 was also higher in the NIHSS $\geq 6$ group $(20.4 \%)$ than in the NIHSS $<6$ group (8.3\%). However, rs699 did not correlate with the NIHSS scores of the ICH group (Table V). Furthermore, rs4762 and rs699 did not correlate with the MBI scores of the ICH group (data not shown). In the IS group, rs4762 and rs699 were not associated with NIHSS and MBI scores, respectively (data not shown). These results suggest that rs4762 may contribute to the neurological functional levels of the ICH patients.

Linkage disequilibrium and haplotypes. Haploview 4.2 was used to estimate the LD block and haplotypes between rs4762 
Table IV. Genotype and allele frequencies of AGT SNPs in ICH and control subjects.

\begin{tabular}{|c|c|c|c|c|c|c|c|}
\hline SNP & Genotype/allele & $\begin{array}{c}\text { Control } \\
\mathrm{n}(\%)\end{array}$ & $\begin{array}{c}\mathrm{ICH} \\
\mathrm{n}(\%)\end{array}$ & Model & OR $(95 \% \mathrm{CI})$ & P-value & $\begin{array}{c}\text { Fisher's } \\
\text { exact } \\
\text { P-value }\end{array}$ \\
\hline \multirow[t]{10}{*}{ rs4762 (T207M) } & Genotype & & & & & & \\
\hline & $\mathrm{C} / \mathrm{C}$ & $247(82.1)$ & $55(71.4)$ & Codominant1 & $1.72(0.93-3.19)$ & 0.08 & \\
\hline & $\mathrm{C} / \mathrm{T}$ & $50(16.6)$ & $19(24.7)$ & Codominant2 & $3.10(0.63-15.17)$ & 0.12 & 0.13 \\
\hline & $\mathrm{T} / \mathrm{T}$ & $4(1.3)$ & $3(3.9)$ & Dominant & $1.83(1.01-3.30)$ & 0.05 & \\
\hline & & & & Recessive & $2.75(0.57-13.35)$ & 0.22 & 0.15 \\
\hline & & & & Overdominant & $1.66(0.90-3.07)$ & 0.11 & \\
\hline & & & & Log-additive & $1.73(1.04-2.89)$ & 0.038 & \\
\hline & Allele & & & & & & \\
\hline & $\mathrm{C}$ & $544(90.4)$ & $129(83.8)$ & & 1 & & \\
\hline & $\mathrm{T}$ & $58(9.6)$ & $25(16.2)$ & & $1.82(1.10-3.02)$ & 0.021 & \\
\hline \multirow[t]{10}{*}{ rs699 (M699T) } & Genotype & & & & & & \\
\hline & $\mathrm{C} / \mathrm{C}$ & $196(65.5)$ & $53(68.8)$ & Codominant1 & $0.84(0.47-1.48)$ & 0.42 & \\
\hline & $\mathrm{C} / \mathrm{T}$ & $98(32.8)$ & $21(27.3)$ & Codominant 2 & $2.45(0.55-10.86)$ & 0.29 & 0.38 \\
\hline & $\mathrm{T} / \mathrm{T}$ & $5(1.7)$ & $3(3.9)$ & Dominant & $0.91(0.53-1.58)$ & 0.75 & \\
\hline & & & & Recessive & $2.58(0.59-11.37)$ & 0.23 & 0.21 \\
\hline & & & & Overdominant & $0.81(0.46-1.43)$ & 0.46 & \\
\hline & & & & Log-additive & $1.02(0.62-1.66)$ & 0.95 & \\
\hline & Allele & & & & & & \\
\hline & $\mathrm{C}$ & $490(81.9)$ & $127(82.5)$ & & 1 & & \\
\hline & $\mathrm{T}$ & $108(18.1)$ & 27 (18.5) & & $0.97(0.61-1.54)$ & 0.88 & \\
\hline
\end{tabular}

AGT, angiotensinogen; SNP, single nucleotide polymorphism; ICH, intracerebral hemorrhage; n, number; OR, odds ratio; CI, confidence interval. P-values were evaluated via logistic regression analyses adjusting for age and gender. The Fisher's exact P-value was used if the number was $<5$. Bold numbers indicate significant associations.

and rs699 of the AGT gene. The LD block was moderately made between the two tested SNPs $\left(D^{\prime}=0.707\right.$ and $r^{2}=0.012$ in the control group; $\mathrm{D}^{\prime}=0.701$ and $\mathrm{r}^{2}=0.013$ in the IS group; and $\mathrm{D}^{\prime}=0.793$ and $\mathrm{r}^{2}=0.017$ in the $\mathrm{ICH}$ group). We also investigated the association between the haplotypes of these two SNPs and stroke. In Table VI, the frequencies of CC, CT, and TC haplotypes are shown to be $0.714-0.717,0.176-0.178$, and $0.101-0.107$, respectively. The TC haplotype differed between the ICH group and the controls $(\mathrm{P}=0.014)$, but not between the IS group and the controls. These results suggest that the haplotype of rs4762 and rs699 may be associated with the development of ICH.

\section{Discussion}

In the CNS, AGT is mainly distributed in glial cells in close proximity to renin-containing neurons and is also expressed in astrocytes $(28,29)$. The variant of AGT is considered to be a risk factor in various diseases and to be significant in body fluid homeostasis. In the study by Hajjar et al (30), which investigated cerebral blood flow regulation, the rs699 SNP (M268T) was associated with vasoreactivity in Caucasians. Buroker et al (31) reported that the AGT 268M allele was associated with mountain sickness. Gomez-Gallego et al (32) suggested that the C allele of M268T may favor power sports performance. A study by Yugar-Toledo et al (33) showed that carriers of the $268 \mathrm{~T}$ allele were at increased risk for resistant hyperten- sion, particularly if they were older than 50 years. However, Conen et al (34) reported that rs699 was not associated with blood pressure progression and incident hypertension in a large cohort of Caucasian women. Underwood et al (35) revealed that minor allele carriers of rs699 were associated with significantly decreased level of insulin resistance when assessed with the homeostasis model assessment of insulin resistance. However, Conen et al (36) reported a lack of association between rs699 and incident type 2 diabetes. Ahluwalia et al (37) demonstrated that the frequencies of T allele and MT/TT genotype in rs699 were higher and associated with increased risk of diabetic nephropathy in Asian Indians. A study by Wang et al (38) indicated that rs699 may confer a predisposition to acquired atrial fibrillation in Han Chinese. Freitas et al (39) found that the rs699 TT genotype increased coronary artery disease (CAD) risk in subjects with hypertension and dyslipidemia. In addition, Tsai et al (40) reported that the effect of the AGT gene haplotype on CAD disease risk increased significantly in females with hypertension. Zakrzewski-Jakubiak et al (41) demonstrated that the haplotype between variant allele of rs4762 and variant allele of rs699 was associated with heart failure. However, Renner et al (42) reported that the genotypes and haplotypes of rs4762 and rs699 did not correlate with hypertension, CAD and myocardial infarction.

Focusing on stroke, Saidi et al (26) reported that rs699 was associated with IS in Tunisians, but rs4762 was not. Um 
Table V. Genotype and allele frequencies of AGT SNPs in ICH subgroups according to NIHSS scores.

\begin{tabular}{|c|c|c|c|c|c|c|c|}
\hline SNP & Genotype/allele & $\begin{array}{c}\text { NIHSS }<6 \\
n(\%)\end{array}$ & $\begin{array}{c}\text { NIHSS } \geq 6 \\
n(\%)\end{array}$ & Model & OR $(95 \%$ CI) & P-value & $\begin{array}{c}\text { Fisher's } \\
\text { exact } \\
\text { P-value }\end{array}$ \\
\hline \multirow[t]{10}{*}{ rs4762 (T207M) } & Genotype & & & & & & \\
\hline & $\mathrm{C} / \mathrm{C}$ & $21(87.5)$ & $31(63.3)$ & Codominant 1 & $6.33(1.25-32.13)$ & 0.035 & 0.039 \\
\hline & $\mathrm{C} / \mathrm{T}$ & $2(8.3)$ & $16(32.6)$ & Codominant 2 & $1.81(0.14-23.25)$ & 0.81 & 1.00 \\
\hline & $\mathrm{T} / \mathrm{T}$ & $1(4.2)$ & $2(4.1)$ & Dominant & $4.85(1.19-19.65)$ & 0.015 & \\
\hline & & & & Recessive & $1.21(0.10-15.09)$ & 0.88 & 1.00 \\
\hline & & & & Overdominant & $6.09(1.21-30.55)$ & 0.011 & \\
\hline & & & & Log-additive & 3.01 (0.94-9.62) & 0.039 & \\
\hline & Allele & & & & & & \\
\hline & $\mathrm{C}$ & 44 (91.7) & 78 (79.6) & & 1 & & \\
\hline & $\mathrm{T}$ & $4(8.3)$ & $20(20.4)$ & & $2.82(0.91-8.78)$ & 0.07 & \\
\hline \multirow[t]{10}{*}{ rs699 (M699T) } & Genotype & & & & & & \\
\hline & $\mathrm{C} / \mathrm{C}$ & $16(66.7)$ & $35(71.4)$ & Codominant 1 & $0.62(0.19-2.00)$ & 0.67 & \\
\hline & $\mathrm{C} / \mathrm{T}$ & $7(29.2)$ & $12(24.5)$ & Codominant 2 & $0.59(0.05-7.51)$ & 0.94 & 1.00 \\
\hline & $\mathrm{T} / \mathrm{T}$ & $1(4.2)$ & $2(4.1)$ & Dominant & $0.62(0.20-1.89)$ & 0.40 & \\
\hline & & & & Recessive & $0.69(0.06-8.45)$ & 0.78 & 1.00 \\
\hline & & & & Overdominant & $0.64(0.20-2.04)$ & 0.46 & \\
\hline & & & & Log-additive & $0.69(0.27-1.72)$ & 0.42 & \\
\hline & Allele & & & & & & \\
\hline & $\mathrm{C}$ & $39(81.3)$ & $82(83.7)$ & & 1 & & \\
\hline & $\mathrm{T}$ & $9(18.8)$ & $16(16.3)$ & & $0.85(0.34-2.08)$ & 0.72 & \\
\hline
\end{tabular}

AGT, angiotensinogen; SNP, single nucleotide polymorphism; NIHSS, National Institutes of Health Stroke Survey; ICH, intracerebral hemorrhage; n, number; OR, odds ratio; CI, confidence interval. P-values were evaluated via logistic regression analyses adjusting for age and gender. The Fisher's exact $\mathrm{P}$-value was used if the number was $<5$. Bold numbers indicate significant associations.

Table VI. Haplotype analysis of AGT SNPs in stroke and control subjects.

\begin{tabular}{|c|c|c|c|c|c|c|c|c|}
\hline \multirow[b]{2}{*}{ Patients } & \multirow[b]{2}{*}{ Haplotype } & \multirow[b]{2}{*}{ Frequency } & \multicolumn{2}{|c|}{ Stroke } & \multicolumn{2}{|c|}{ Control } & \multirow[b]{2}{*}{$\chi^{2}$} & \multirow[b]{2}{*}{ P-value } \\
\hline & & & + & - & + & - & & \\
\hline \multirow[t]{3}{*}{ Intracebral hemorrhage } & $\mathrm{CC}$ & 0.714 & 102.2 & 51.8 & 437.4 & 164.6 & 2.369 & 0.12 \\
\hline & $\mathrm{CT}$ & 0.176 & 26.8 & 127.2 & 106.6 & 495.4 & 0.008 & 0.93 \\
\hline & $\mathrm{TC}$ & 0.107 & 24.8 & 129.2 & 55.8 & 546.2 & 5.992 & 0.014 \\
\hline \multirow[t]{3}{*}{ Ischemic stroke } & $\mathrm{CC}$ & 0.717 & 165.6 & 74.4 & 437.8 & 164.2 & 1.166 & 0.28 \\
\hline & $\mathrm{CT}$ & 0.178 & 43.4 & 196.6 & 106.2 & 495.8 & 0.022 & 0.88 \\
\hline & $\mathrm{TC}$ & 0.101 & 30 & 210 & 55.4 & 546.6 & 2.036 & 0.15 \\
\hline
\end{tabular}

Haplotype comprises rs4762 and rs699. Haplotype distributions in stroke and control subjects were estimated using Haploview 4.2. The bold number indicates a significant association. SNP, single nucleotide polymorphism; AGT, angiotensinogen.

et al (27) revealed that the genotype distribution of rs699 differed between Korean IS patients and controls. Brenner et al (24) showed that $207 \mathrm{M}$ had a weakly protective effect against brain infarction and 268M was strongly associated with 5-year vascular mortality in Caucasian patients. However, Sethi et al (43) reported that rs4762 and rs699 were not associated with increased risk for IS in Europeans. These observed discrepancies may result from differences in ethnicities and/or sample sizes. Our results revealed that the genotypes, alleles and haplotypes of rs4762 and rs699 were not correlated with the development of IS in the Korean population. This agrees with results of the study by Sethi et al (43) However, our data revealed that rs 4762 was associated with the development of $\mathrm{ICH}$ and with the NIHSS scores of the ICH group.

The AGT protein (UniProt ID, P01019) comprises 485 amino acids (AAs) with a signal peptide (from 1 to 33 AAs), AGT chain (from 34 to 485 AAs) and several peptides, including angiotensin-1 (from 34 to 43 AAs), angiotensin-2 (from 34 to 41 AAs) 
and angiotensin-3 (from 35 to $41 \mathrm{AAs}$ ) (http://www.uniprot. org/uniprot). Two missense SNPs (rs4762, ACG207ATG, T207M and rs699, ATG268ACG, M268T) are located in the AGT chain. The underlined characters in ACG207ATG and ATG268ACG indicate nucleotide substitution at each site, resulting in threonine-to-methionine and methionine-tothreonine exchanges in codon 207 and codon 268, respectively. In the HapMap (http://www.hapmap.org/; genome build 36) and the SNP database, the $\mathrm{C}$ and $\mathrm{T}$ allele frequencies in the rs4762 SNP are reported to be 0.891 and 0.109 in Europeans, 0.969-0.959 and 0.031-0.041 in Sub-Saharan Africans, 0.918 and 0.082 in Japanese, 0.919-0.863 and 0.081-0.138 in Chinese and 0.889 and 0.111 in Koreans, respectively. In our control group, the $\mathrm{C}$ and $\mathrm{T}$ allele frequencies were 0.904 and 0.096 , respectively, which are similar to those observed in Asian populations. The $\mathrm{T}$ and $\mathrm{C}$ allele frequencies in the rs699 SNP were reported to be 0.588 and 0.412 in Europeans, $0.255-0.080$ and 0.920-0.745 in Sub-Saharan Africans, 0.163 and 0.837 in Japanese and 0.134-0.279 and 0.866-0.721 in Chinese, respectively. In our control group, the $\mathrm{T}$ and $\mathrm{C}$ allele frequencies were 0.181 and 0.819 , respectively, which are similar to those observed in Japanese individuals. The $\mathrm{C}$ allele frequencies of rs699 in Asians are higher than in Europeans. The rs699 SNP shows ethnic differences in its allele distributions. Our results revealed that the TC haplotypes between rs 4762 and rs699 were associated with ICH. Considering the ethnic differences in the C allele frequencies of rs699, our results may, in part, explain a medical phenomenon concerning the high ICH incidence in Asians. To the best of our knowledge, this is the first study of whether two missense SNPs (rs4762 and rs699) of AGT are associated with the development and clinical subgroups of stroke (IS and ICH) in a Korean population. We found that a missense SNP rs4762 (T207M) was associated with the development of ICH ( $\mathrm{P}=0.038$ in log-additive model, $\mathrm{P}=0.021$ in allele distributions). The $\mathrm{T}$ allele frequency of $\mathrm{T} 207 \mathrm{M}$ was higher in the ICH group (16.2\%) than in the control group (9.6\%). Moreover, T207M was related to the NIHSS scores of ICH $(\mathrm{P}=0.039$ in codominant $1, \mathrm{P}=0.015$ in dominant, $\mathrm{P}=0.011$ in overdominant, and $\mathrm{P}=0.039$ in log-additive models). In addition, the TC haplotype between rs4762 and rs699 differed between the ICH and control groups $(\mathrm{P}=0.014)$. This study has certain limitations. First, the number of cases is low. In addition, we lacked age-matched samples among the study groups. Additional studies of a large number of cases and/or age-matched populations are required to confirm our results.

The present study suggests that a missense SNP (rs4762, T207M) of the AGT gene may be associated with the development and neurological functional levels of ICH in a Korean population.

\section{Acknowledgements}

This study was funded by Kyung Hee University's program for young medical researchers in 2009 (KHU-20091460).

\section{References}

1. Grysiewicz RA, Thomas K and Pandey DK: Epidemiology of ischemic and hemorrhagic stroke: incidence, prevalence, mortality, and risk factors. Neurol Clin 26: 871-895, vii, 2008.
2. van Asch CJ, Luitse MJ, Rinkel GJ, et al: Incidence, case fatality, and functional outcome of intracerebral haemorrhage over time, according to age, sex, and ethnic origin: a systematic review and meta-analysis. Lancet Neurol 9: 167-176, 2010.

3. Wolf PA, Belanger AJ and D'Agostino RB: Management of risk factors. Neurol Clin 10: 177-191, 1992.

4. Lanktree MB, Dichgans M and Hegele RA: Advances in genomic analysis of stroke: what have we learned and where are we headed? Stroke 41: 825-832, 2010.

5. Ikram MA, Seshadri S, Bis JC, et al: Genomewide association studies of stroke. N Engl J Med 360: 1718-1728, 2009.

6. Somarajan BI, Kalita J, Mittal B and Misra UK: Evaluation of MTHFR C677T polymorphism in ischemic and hemorrhagic stroke patients. A case-control study in a Northern Indian population. J Neurol Sci 304: 67-70, 2011.

7. Tao HM, Chen GZ, Lu XD, Chen GP and Shao B: TGF- $\beta 1$ 869T/C polymorphism and ischemic stroke: sex difference in Chinese. Can J Neurol Sci 37: 803-807, 2010.

8. Kim NS, Ko MM, Cha MH, Oh SM and Bang OS: Age and sex dependent genetic effects of neuropeptide Y promoter polymorphism on susceptibility to ischemic stroke in Koreans. Clin Chim Acta 411: 1243-1247, 2010.

9. Han IB, Kim OJ, Ahn JY, et al: Association of methylenetetrahydrofolate reductase (MTHFR 677C $>$ T and 1298A $>$ C) polymorphisms and haplotypes with silent brain infarction and homocysteine levels in a Korean population. Yonsei Med J 51: 253-260, 2010.

10. Kim OJ, Hong SP, Ahn JY, et al: Influence of combined methionine synthase (MTR 2756A > G) and methylenetetrahydrofolate reductase (MTHFR 677C $>$ T) polymorphisms to plasma homocysteine levels in Korean patients with ischemic stroke. Yonsei Med J 48: 201-209, 2007.

11. Kim YS, Yoo JH and Lee BC: Susceptibility for ischemic stroke in Korean population is associated with polymorphisms of the $\mathrm{Fc}$ gamma receptor IIA. Blood Coagul Fibrinolysis 20: 353-357, 2009

12. Lee BC, Ahn SY, Doo HK, et al: Susceptibility for ischemic stroke in Korean population is associated with polymorphisms of the interleukin-1 receptor antagonist and tumor necrosis factor-alpha genes, but not the interleukin-lbeta gene. Neurosci Lett 357: 33-36, 2004.

13. Lee BC, Lee H, Park HK, Yang JS and Chung JH: Susceptibility for ischemic stroke in four constitution medicine is associated with polymorphisms of FCGR2A and IL1RN genes. Neurol Res 32 (Suppl 1): 43-47, 2010.

14. Park SA, Park BL, Park JH, et al: Association of polymorphisms in thromboxane $\mathrm{A} 2$ receptor and thromboxane A synthase 1 with cerebral infarction in a Korean population. BMB Rep 42: 200-205, 2009.

15. Kim MK, Kim JT, Choi SM, et al: Phosphodiesterase 4D gene and risk of noncardiogenic ischemic stroke in a Korean population. J Korean Med Sci 24: 307-310, 2009.

16. Um JY and Kim HM: Polymorphisms of RANTES and IL-4 genes in cerebral infarction. J Mol Neurosci 37: 1-5, 2009.

17. Lee SH, Kim MK, Park MS, et al: beta-Fibrinogen gene -455 G/A polymorphism in Korean ischemic stroke patients. J Clin Neurol 4: 17-22, 2008.

18. Kang SY and Lee WI: Apolipoprotein E polymorphism in ischemic stroke patients with different pathogenetic origins. Korean J Lab Med 26: 210-216, 2006.

19. Shin BS, Oh SY, Kim YS and Kim KW: The paraoxonase gene polymorphism in stroke patients and lipid profile. Acta Neurol Scand 117: 237-243, 2008.

20. Lee BC, Doo HK, Ahn SY, et al: Peroxisome proliferatoractivated receptor-gamma Pro12Ala polymorphism is associated with the susceptibility to ischemic stroke in Taeeumin classified by Sasang medicine. Neurol Res 29 (Suppl 1): S32-S37, 2007.

21. Kim Y, Kim JH, Nam YJ, et al: Klotho is a genetic risk factor for ischemic stroke caused by cardioembolism in Korean females. Neurosci Lett 407: 189-194, 2006.

22. Seo JC, Han SW, Yin CS, et al: Evaluation of a Apo-1/Fas promoter polymorphism in Korean stroke patients. Exp Mol Med 34: 294-298, 2002.

23. Marciante KD, Bis JC, Rieder MJ, et al: Renin-angiotensin system haplotypes and the risk of myocardial infarction and stroke in pharmacologically treated hypertensive patients. Am J Epidemiol 166: 19-27, 2007.

24. Brenner D, Labreuche J, Poirier O, Cambien F and Amarenco P; GENIC Investigators: Renin-angiotensin-aldosterone system in brain infarction and vascular death. Ann Neurol 58: 131-138, 2005. 
25. Hong SH, Park HM, Ahn JY, et al: ACE I/D polymorphism in Korean patients with ischemic stroke and silent brain infarction. Acta Neurol Scand 117: 244-249, 2008

26. Saidi S, Mallat SG, Almawi WY and Mahjoub T: Association between renin-angiotensin-aldosterone system genotypes and haplotypes and risk of ischemic stroke of atherosclerotic etiology. Acta Neurol Scand 119: 356-363, 2009.

27. Um JY, Moon KS, Lee KM, et al: Polymorphism of angiotensinconverting enzyme, angiotensinogen, and apolipoprotein E genes in Korean patients with cerebral infarction. J Mol Neurosci 21: 23-28, 2003.

28. Morimoto S, Cassell MD, Beltz TG, et al: Elevated blood pressure in transgenic mice with brain-specific expression of human angiotensinogen driven by the glial fibrillary acidic protein promoter. Circ Res 89: 365-372, 2001.

29. Sherrod M, Davis DR, Zhou X, Cassell MD and Sigmund CD: Glial-specific ablation of angiotensinogen lowers arterial pressure in renin and angiotensinogen transgenic mice. Am J Physiol Regul Integr Comp Physiol 289: R1763-R1769, 2005.

30. Hajjar I, Sorond F, Hsu YH, et al: Renin angiotensin system gene polymorphisms and cerebral blood flow regulation: the MOBILIZE Boston study. Stroke 41: 635-640, 2010.

31. Buroker NE, Ning XH, Zhou ZN, et al: Genetic associations with mountain sickness in Han and Tibetan residents at the QinghaiTibetan Plateau. Clin Chim Acta 411: 1466-1473, 2010.

32. Gomez-Gallego F, Santiago C, Gonzalez-Freire M, et al: The $\mathrm{C}$ allele of the AGT Met235Thr polymorphism is associated with power sports performance. Appl Physiol Nutr Metab 34: 1108-1111, 2009.

33. Yugar-Toledo JC, Martin JF, Krieger JE, et al: Gene variation in resistant hypertension: multilocus analysis of the angiotensin 1 -converting enzyme, angiotensinogen, and endothelial nitric oxide synthase genes. DNA Cell Biol 30: 555-564, 2011.

34. Conen D, Glynn RJ, Buring JE, Ridker PM and Zee RY: Association of renin-angiotensin and endothelial nitric oxide synthase gene polymorphisms with blood pressure progression and incident hypertension: prospective cohort study. J Hypertens 26: 1780-1786, 2008.
35. Underwood PC, Sun B, Williams JS, et al: The association of the angiotensinogen gene with insulin sensitivity in humans: a tagging single nucleotide polymorphism and haplotype approach. Metabolism 60: 1150-1157, 2011.

36. Conen D, Glynn RJ, Buring JE, Ridker PM and Zee RY: Renin-angiotensin and endothelial nitric oxide synthase gene polymorphisms are not associated with the risk of incident type 2 diabetes mellitus: a prospective cohort study. J Intern Med 263: 376-385, 2008

37. Ahluwalia TS, Ahuja M, Rai TS, et al: ACE variants interact with the RAS pathway to confer risk and protection against type 2 diabetic nephropathy. DNA Cell Biol 28: 141-150, 2009.

38. Wang QS, Li YG, Chen XD, et al: Angiotensinogen polymorphisms and acquired atrial fibrillation in Chinese. J Electrocardiol 43: 373-377, 2010.

39. Freitas AI, Mendonca I, Brion M, et al: RAS gene polymorphisms, classical risk factors and the advent of coronary artery disease in the Portuguese population. BMC Cardiovasc Disord 8: $15,2008$.

40. Tsai CT, Hwang JJ, Lai LP, et al: Interaction of gender, hypertension, and the angiotensinogen gene haplotypes on the risk of coronary artery disease in a large angiographic cohort. Atherosclerosis 203: 249-256, 2009.

41. Zakrzewski-Jakubiak M, de Denus S, Dube MP, et al: Ten reninangiotensin system-related gene polymorphisms in maximally treated Canadian Caucasian patients with heart failure. Br J Clin Pharmacol 65: 742-751, 2008.

42. Renner W, Nauck M, Winkelmann BR, et al: Association of angiotensinogen haplotypes with angiotensinogen levels but not with blood pressure or coronary artery disease: the Ludwigshafen Risk and Cardiovascular Health Study. J Mol Med (Berl) 83: 235-239, 2005.

43. Sethi AA, Tybjaerg-Hansen A, Gronholdt ML, et al: Angiotensinogen mutations and risk for ischemic heart disease, myocardial infarction, and ischemic cerebrovascular disease. Six case-control studies from the Copenhagen City Heart Study. Ann Intern Med 134: 941-954, 2001. 